\title{
Community Development: The Way Forward for Social Work in Disaster Management. Critical Essay
}

\author{
Jennifer Woods \\ Charles Sturt University, Wagga Wagga, Australia \\ *Corresponding Author: jwoods@csu.edu.au
}

\begin{abstract}
Community development is the way forward for social work. Economic rationalism, smaller governments and possible climate changes mean more crises and less state resources, urbanisation means more densely populated communities, especially in coastal zones and adjacent waterways and coupled together, an increased need for social work interventions. Certainly, using readily available resources and preparing for potential negative events makes community development an ethical and appropriate means of dealing with issues of community for social workers. Even for disaster management where social work has been traditionally located at the crisis stage in a role of assisting with psychological stress there lies an opportunity to focus more in the community development context, not only utilising available social capital for recovery but for assisting with building capacity and thus creating solid foundations for the future of the community. The recent edited book, Community Work: Theories, Experiences and Challenge (Goel, Pulla and Francis, 2014) provides a compilation of many relevant articles that explore the concept of community development and the way in which social workers can embrace this framework for ethical service provision in contemporary Australian communities. A recent paper by Rowlands (2013) reiterates the ability of social work to work at the nexus between communities and governments in disaster management to adopt a community development approach which not only enables communities to move forward but empowers the community to assist itself. A community development approach involving social work underpinned with resilience and strengths based theories allows for ethical, professional practice within AASW guidelines that enables communities to grow and thrive as well as survive disasters of the future.
\end{abstract}

Keywords Community Development, Resilience, Strengths Based, Disaster Management

Goel, K., Pulla, V. and Francis, A. (Eds.) (2014). Community work: Theories, Experience and Challenge. Bangalore: Niruta Publications.

Rowlands, A.(2013). Disaster Recovery Management in Australia and the Contribution of Social Work. Journal of
Social Work in Disability \& Rehabilitation. 12(1-2), pp 19-38.

For disaster management, social work is well located at the nexus between governance and communities so as to promote and facilitate resilience which is now embedded in national disaster management policy with the recognition of the inability of government to provide the total resources required for disaster response, recovery and preparedness. With a legacy of two decades of neo-liberal political ideology which inevitably leads to decreased state intervention, a rise in the role of social work underpinned with a community development framework is not only appropriate for the profession which has strong links to concepts such as social justice, equity and the alleviation of poverty but is also a positive matching of professional social work ethics, theoretical perspectives and skills. Social work with a community development focus allows for the building of resilience which pairs with strengths based theories to facilitate social work in working with individuals and communities to enhance their coping and capacities to empower and strengthen. Urbanisation has seen population densities increase and these urban areas are predominantly located in desirable coastal areas and along waterways, for aesthetics as well as necessity. Climate changes also are likely to have an impact with rising sea levels, increased temperatures leading more demand for water supply and increased intensity of natural disaster events. These factors combine to present a challenge for contemporary governments who have responded with frameworks and policies that require collaborative efforts of governments, non-government organisations, communities and individuals to work to create sustainable communities that can survive natural disasters with limited government resources and utilising their own strengths and capacities. Community development provides the ideal framework for social work practitioners to participate meaningfully, professionally and ethically.

\section{Why Community Development for Disaster Management?}

Economic rationalism, widely accepted globally, with a 
focus on market driven economies which endorse private ownership, less state interventions and individual responsibility have created a niche for community development as the way of social work into the future (Ife and Tesorio, 2006). Goel (2014, p.5-6) in the edited text Community work: Theories, Experience and Challenges comments that this neo-liberalism and the policies that it embraces have failed to facilitate the welfare state in meeting the needs of the people it was built to serve as evidenced by the widening gaps between rich and poor, ongoing poverty and increased marginalisation of people across the globe. Goel (2014, p.6) further states that these issues are best addressed at this point by community development which facilitates the development of community based structures that can compensate for bureaucratic structures lost to neo-liberal policy changes in the last two decades. Francis, Pulla and Goel (2014, p. 164) in their chapter on Community Development and Mental Health Promotion, state that community development is the way in which social and political changes can be coordinated. Similarly Rowlands (2013, p. 20) discusses the responsibility of disaster management as spread over both national and state governments and the recent move towards community resilience and community responsibility and participating in all phases of the disaster management framework, linking neatly the concepts of community development and disaster management.

Albrito (2012) outlines the pertinence of the concept of urbanisation to community development driven disaster recover management with her discussion about the increased number of cities now having evolved in low elevation, coastal zones coupled with population growth and insufficient development of infrastructure required to cope with this influx of people. Albrito (2012) describes one consequence with regard to disaster management is that of more significant impact from disasters including economic loss and also loss of life. Bhadra and Pulla (2014, p. 105) in the edited book Community work: Theories, Experience and Challenges note the importance of social work at the interface of disaster management as one of provision of immediate relief from the psychological trauma and collaborative efforts with emergency service responders but also delve into the role of community development social work as having a much lens that allows for social work to have an impact at all stage of the disaster management process. Clearly this role of empowerment, capacity and resilience building is vital for ethical social work practice as urbanisation leads to bigger communities with less infrastructure and increased impact from disaster. Rowlands (2013, p. 20) comments on the case of Cyclone Yasi as compared with that of Cyclone Tracey, two of the most significant natural disasters in Australian history, and notes the impact that community development focussed frameworks have had in emergency response, allowing for the engagement of the community, increased intensity of information dissemination and in lieu of evacuation and relocation post disaster, collaborative work with the community for the process of recovery. Rowlands (2013, p. 25) also discusses the mass convergence of volunteers post Queensland flooding in 2011 and in this example we can see both the effects of urbanisation in the intensity of impact and the numbers of people involved but also in the benefit of community development work whereby these increased populations also serve as capital for recovery work and an ideal place for social work to situate itself in organisational management as well as crisis intervention in the informal setting of the area of impact.

Francis and Pulla (2014, p.254) in the text Community work: Theories, Experience and Challenges discuss the fact that we live in times of uncertainty and of crisis and use a quote from Ife (2003) which indicates that in times of crisis there exists also time of opportunity for transformation, and then further contemplate the climate change issue which encompasses the uncertainty which communities now face in regard to their future and the climate. Climate change, whilst a hotly debated concept, is accepted by social work as an appropriate issue for social workers in community development with social workers having an inherent place in helping communities to deal with this uncertainty due to their ethical commitments to principles and values such as empowerment and social equity (Tan and Yuen, 2013). With practice embedded in human rights and social justice, utilising community development frameworks is a logical solution to dealing with issues of climate change and community uncertainty (Francis and Pulla 2014, p.254, Gopalkrishnan, 2014, p.18). Gopalkrishnan (2014, p. 16) in the edited book Community work: Theories, Experience and Challenges neatly links the issue of climate change inducing increased frequency and intensity of natural disaster and neo-liberalism which exacerbates the scale and intensity of social issues such as poverty, unemployment and social inequity. Not only does neo-liberalism increase the impact of disasters with lessened funding and infrastructure but it also places the emphasis on recovery at the individual level. Rowlands (2013, p. 24) further links the responsibility of disaster management to community resilience, creating the place for community development focussed social work that harnesses the skills and capacities the community already has in situ.

\section{How Does Community Development Support Disaster Management?}

With disasters occurring globally, linked to perhaps climate change and urbanisation and with impact that is correlated with neo-liberal policy that decreases the level of organisational assistance and infrastructure available, the role for community development focussed social workers is growing. The Australian government acknowledges this increase in frequency and intensity of natural disasters and also promotes policy that requires participation and 
responsibility from individuals and communities so as to build what is considered resilient communities (Commonwealth of Australia, 2011, p. 2). The community development practitioner can work with communities at each stage of the disaster management process, prevention, mitigation, preparedness, response, rehabilitation, reconstruction and recovery (Bhadra and Pulla, 2014, p. 104) and utilising a number of strategies; community meeting, community events, public awareness campaigns, capacity building projects (Bhadra and Pulla, 2014, p. 113-114), as well as safety-net groups (Francis and Zuchowski, 2014, p. 87).

"Given the increasing regularity and severity of natural disasters, Australian Governments have recognised that a national, coordinated and cooperative effort is required to enhance Australia's capacity to withstand and recover from emergencies and disasters. A disaster resilient community is one that works together to understand and manage the risks that it confronts. Disaster resilience is the collective responsibility of all sectors of society, including all levels of government, business, the non-government sector and individuals" (Commonwealth of Australia, 2011, p. IV).

This quote from the National Strategy for Disaster Resilience demonstrates the top down ideology that endorses collaborative effort from each participant for disaster recovery and regardless of whether this is merely a cost cutting political measure or an effort to enhance the inherent coping and resilience that communities and individuals demonstrate in disaster situations, this is national policy and as such social work is bound. Further, in line with the National Disaster Resilience Framework (Attorney Generals Department, 2009, p.2) social work can participate in the building of resilience for communities as community development work in the following areas; as NGO's to strengthen capacities inherent to communities, to work to empower individuals and communities, to advocate alongside communities for appropriate development and infrastructure, intervention at the response and recovery stages that fosters empowerment and resilience and to work at the nexus between governance and community for building communities that can better endure disaster.

\section{The Implications for Social Work, Community Development and the North Wagga Flood 2011}

The impact of the La Nina across Eastern Australia was such that much of the eastern states experienced some of the worst flooding in recorded history. The same can be said for North Wagga, NSW, a distinct and small community of around 200 homes that was some of the original settlement for what is now a major inland city. Surrounded by levee banks built after the 1974 floods (completed in the 1990's), North Wagga was inundated when floodwaters from the Murrumbidgee catchment overtopped the levee by a substantial amount flooding the entire suburb and almost all of the homes, schools and businesses. In the two years since the event, which was classified as a natural disaster by the Australian federal government, North Wagga has rebuilt considerably. The majority of homes have been repaired or rebuilt with some homeowners choosing to elevate and some to flood proof. The businesses have regained momentum and the schools are both again fully functioning. There are visible signs of community development including the new community park and the community hall refurbishment. Alongside this readily visible evidence, there has been considerable media documentation, particularly at the two year mark, which also illustrates recovery and community development involvement in same. Recent media articles document the naming of the new park with a free community BBQ and an outdoor movie night as a collaborative effort between the residents association and the football club.

Community development is very much the framework in use by the residents of North Wagga as they recover and rebuild from the 2011 flood. Significant is the funding received from the local council to perform an arts based community development project as described by Riggs and Pulla (2014, p. 30-38) in the recent edited book Community work: Theories, Experience and Challenges, as an appropriate means to not only building capacity for the community but as a means to trauma recovery, inducing social inclusion, promoting collaboration and to restore hope and vision of a positive future. The North Wagga community art project will involve local children and a retired local teacher to produce art work that will be displayed in the local park. For social work with a community development focus, the example of North Wagga coupled with the information form Riggs and Pulla (2014) suggest a role for social work that involves group work, sourcing funding and liaison with existing community groups to endorse arts based community development projects for resilience building post disaster recovery phase as well as the preparedness phase for communities at risk of natural disaster such as those communities located on flood plains and in increasingly urbanised coastal areas.

Discussion regarding safety-net groups by Francis and Zuchowski (2014, p. 89) in the edited text Community work: Theories, Experience and Challenges, relate particularly well to discussion about the validity of community development frameworks for social work with regard to disaster management as the notion of safety-net groups as a self help group whose aim is to provide mutual support during crises (Francis and Zuchowski, 2014, p89). Not only do such groups endorse community participation and promote individual and community responsibility taking, they stimulate empowerment and self determination linking together social work, community development and disaster management expectations of resiliency. For North Wagga, there are a number of examples, the local residents association providing support and resources and social networking communities providing online social support.

Penman (2014, p. 59) in the recent edited book Community work: Theories, Experience and Challenges 
discusses the concept of building community capacity through health education with particular reference to grassroots organisations. This concept also applies to the community of North Wagga in the post flood phase as evidenced by the local Women's Health Centre running a series of women's wellness and yoga sessions. The female residents were invited to join for some mediation, discussion groups and yoga with the aim of connecting displaced residents, creating space for narrative and education regarding self care practices useful in the trauma recovery phase. Penman (2014, p.58) specifically endorses health education sessions as a means to share important health promotion information, to connect resources to the people who require them, to encourage proactive participation and to promote empowerment. Another example for post flood disaster work would include the dissemination of health information related to the dangers of floodwater contaminated houses, removal of flood damaged and asbestos containing building materials and community health issues such as substance use and domestic violence that often accompany trauma.

Mugisha, Ssebunnya, Kizza and Kigozi (2014, p.185) in the recent edited book Community work: Theories, Experience and Challenges, discuss microfinance, that being the provision of financial services to the poor including loans, savings, insurance and training, as a positive means to community development. Perhaps not to the same extent, this was evidenced in North Wagga with the ability of residents to receive funds from the donation pool contributed to by the wider community. Again in North Wagga it was possible for residents, particularly those who were uninsured, to purchase building materials at trade prices, a private arrangement organised between the local supplier and the residents association. There is a clear role for social work here for disaster management in the arrangement of financial services, above and beyond those as offered by the Australian Government through either the Department of Human Services or FACs both of which are governed by legislation and applicable to only those who meet the given parameters (Rowlands, 2013).

\section{Conclusions}

Disaster management is occupying an increased status in government discussions both globally and nationally. Increased urbanisation, climate changes and the twenty year history of neo-liberal political ideology combine to create an era which is experiencing increased intensity and frequency of natural disaster events and lessened government resources to facilitate response and recovery. Government are responding to this challenge by embedding their frameworks and policies with the concept of resilience, or the ability to survive these events utilising their own capacities and strengths. Social work with a community development focus is ideally located at the nexus between governments and communities to work in an ethical and professional way to facilitate interventions and programs that enhance resilience by building upon capacities and strengths available to individuals and communities. Not only does community development based disaster management work allow for the response to decreased state interventions in response, recovery and preparedness but it promotes empowerment and self determination for individuals and communities and fulfils the requirements for ethical service provision, positive outcomes for communities at the foremost.

\section{REFERENCES}

Attorney Generals Department (2009). National Disaster Resilience Framework. Retrieved

from :http://www.em.gov.au/Documents/NationalDisasterResilien ceFramework-EndorsedatMCPEM-EM20Nov2009.pdf

Commonwealth of Australia (2011). National strategy for disaster resilience. Canberra: Attorney Generals Department.

Rowlands, A. (2013). Disaster recovery management in Australia and the contribution of social work. Journal of Social Work in Disability and Rehabilitation, 12:1-2, pp. 19-38.

Gopalkrishnan, N. (2014). In response to Globalisation: Community development in social work education. In, Goel, K., Pulla, V. and Francis, A. (Eds.) (2014). Community work: Theories, Experience and Challenge. Bangalore: Niruta Publications.

Francis, A. and Pulla, V. (2014). Community work in the context of uncertainty: Challenges and opportunities. In, Goel, K., Pulla, V. and Francis, A. (Eds.) (2014). Community work: Theories, Experience and Challenge. Bangalore: Niruta Publications.

Francis, A.,Pulla, V. and Goel, K. (2014). Community development and mental health promotion. In, Goel, K., Pulla, V. and Francis, A. (Eds.) (2014). Community work: Theories, Experience and Challenge. Bangalore: Niruta Publications.

Mugisha, J.,Ssebunnya, J.,Kizza, D. and Kigozi, F. (2014). The role of microfinance in supporting people with mental health problems in their recovery: A case study from Uganda.

Ife, J. and Tesorio, F. (2006). Community development: Community-based alternatives in an age of globalisation. (3rd ed.). Frenchs Forest: Pearson Education Australia.

Goel, K. (2014). Understanding community and community development. In, Goel, K., Pulla, V. and Francis, A. (Eds.) (2014). Community work: Theories, Experience and Challenge. Bangalore: Niruta Publications.

Bhadra, S. and Pulla, V. (2014). Community interventions in disasters. In, Goel, K., Pulla, V. and Francis, A. (Eds.) (2014). Community work: Theories, Experience and Challenge. Bangalore: Niruta Publications.

Albrito, P. (2012). Making cities resilient: increasing resilience to disasters at the local level. Journal of Business Continuity and Emergency Planning. 15(43), pp. 291-297.

Francis, A. and Zuchowski, I. (2014). In, Goel, K., Pulla, V. and Francis, A. (Eds.) (2014). Community work: Theories, Experience 
and Challenge. Bangalore: Niruta Publications.

Riggs, A. and Pulla, V. (2014). Visual and Theatre Arts in Community Development. In, Goel, K., Pulla, V. and Francis, A. (Eds.) (2014). Community work: Theories, Experience and Challenge. Bangalore: Niruta Publications.
Penman, J. (2014). Building community capacity through health education at the grassroots. In, Goel, K., Pulla, V. and Francis, A. (Eds.) (2014). Community work: Theories, Experience and Challenge. Bangalore: Niruta Publications. 